\title{
OBITUARY
}

\section{WILLIAM THOMAS HOLMES SPICER}

THE death of Holmes Spicer seems to mark an epoch in ophthalmology in this country for he is almost the last of a small group who were of international fame. Thus he was an immediate link with Streatfeild, Hulke, Tweedy, and Nettleship, and was contemporary with Marcus Gunn, Lang, Lawford, Treacher Collins, and others. His attachment to Nettleship was especially close; he had the greatest respect and admiration for him and was in large measure his natural successor, for he succeeded to his clinic at Moorfields.

Holmes Spicer was a man of great native ability and would have made his mark in any walk of life. $\mathrm{He}$ was born at Saffron Walden in 1860 and was educated at Saffron Walden School, at Queen Elizabeth's School, Barnet, and entered Gonville and Caius, Cambridge, in 1879, obtaining a First Class in the Natural Science Tripos. From Cambridge he went to St. Bartholomew's Hospital where he was at once conspicuous among his contemporaries; he obtained the Brackenbury Scholarship in Surgery, the chief prize of its kind, and was elected President of the Abernethian Society. In 1884 he qualified as M.R.C.S., in 1886 as M.B., and in 1888 he became F.R.C.S. Eng.

For a short time he engaged in general practice in London but soon gave it up for ophthalmology for which he had always had a great liking. He began working at Moorfields, which at that time was in Moorfields before it migrated to its present site, in the Ophthalmic Department of St. Bartholomew's, and in Vienna.

He was appointed to the Moorfields staff in 1898, and on the death of Mr. Vernon was elected Ophthalmic Surgeon to St. Bartholomew's with $\mathrm{Mr}$. Jessop as his senior colleague. $\mathrm{He}$ became Dean of the Medical School at Moorfields in 1899. Much of the popularity and high standing of the Royal London Ophthalmic Hospital as the teaching centre for ophthalmology in the Empire was due to the unostentatious but thorough work of Holmes Spicer as Dean. Quiet and dignified in manner he was possessed of great powers of organization and the wisdom of the measures which he proposed was rarely questioned by his colleagues. These two hospitals took up the greater part of his spare time and he continued his work at each till he attained the age limit; he was consulting surgeon to both at the time of his death ; as well as to the Metropolitan and Victoria Hospital for Children. He joined the Ophthalmological Society of the United Kingdom in 1889, served on the Council 1900-1902, was Librarian from 1907-1912 and Vice- 


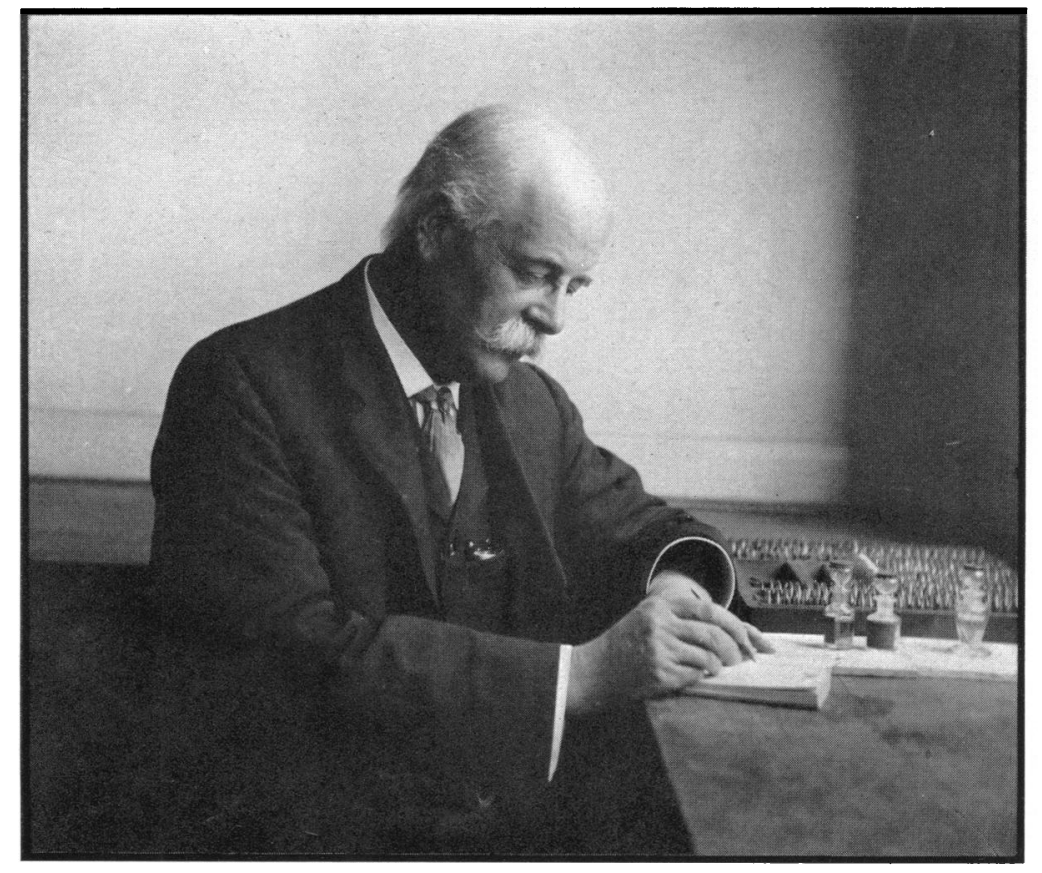

WILLIAM THOMAS HOLMES SPICER 
President, 1910-12. He was also President of the Ophthalmological Section of the Royal Society of Medicine. Late in life he was the first of the Gifford Edmonds Memorial prizewinners, and his essay on "Parenchymatous Keratitis : Interstitial Keratitis : Uveitis Anterior" was the first of the monograph supplements to be published by this Journal. He had a large private practice and was greatly loved by all his patients.

No one could come into contact with him without being conscious of his special charm; his integrity was unassailable and he represented all that was best in our profession. His clinical acumen was outstanding so that his opinion was much sought after and highly esteemed by his colleagues. He wrote nothing without careful thought and deliberation so that everything that came from his pen demanded and received respect. He was a good linguist; at one time a keen motorist; and was for many years a member of the Northwood Golf Club.

His particular interest outside his professional work was in art, and especially in water colour painting at which he was quite exceptionally proficient. I am not aware that he ever held an exhibition of his work but with good reason he might have done so, for not only was he an accomplished colourist but was also a finished draughtsman, a combination seldom found amongst amateurs. Through Mrs. Holmes Spicer's friendship with Sargent he was brought into contact with this great artist and was, I believe, influenced by him. He showed five pictures at the recent Medical Art Society's Exhibition and was present at it.

During the war he was eager to go out to France and was disappointed when it was pointed out that his valuable services had wider scope at home. For many years he served in an advisory capacity to the War Office.

He was also Ophthalmic Surgeon to the Queen Alexandra War Hospital and for nine years served on the War Office Appeal Board.

He had lived a fuil life and has left a deep impression on the ophthalmology of his time : his loss will be deplored by many.

\section{R. Foster MoOre.}

Sir John Parsons writes : "The death of Mr. Holmes Spicer has bereft ophthalmologists of an esteemed colleague and a loyal friend. He brought to his work a sound knowledge of general science, acquired at that best of scientific schools, Cambridge; but in addition he was widely read in literature and history, and endowed with unusual artistic ability and outlook. Coming early under the influence of the most scientific teacher of his time, Edward Nettleship, any high flights of imagination and originality, of which he was fully capable, were co-ordinated and 
controlled by that stern but salutary taskmaster. With his gift of accurate draughtsmanship it was natural that his notes of cases should be profusely illustrated by sketches of abnormal conditions, often revealing to others the true nature of a case in a manner which verbal description alone failed to convey. He was specially interested in the innumerable types of corneal ulcer and opacity; and his Gifford Edmonds Prize Essay on "Parenchymatous Keratitis," etc., published as a monograph by the Brit. Jl. of Ophthal., embodied the work of a lifetime. It is enriched by many exquisite drawings and will ever remain a classical contribution to the subject. On holidays and in retirement he gave free rein to his artistic bent, revelling in the beauties of scenery and architecture, perpetuating many scenes with no mean skill. One such sketch, which he gave to me, has been highly praised by competent critics, and there is little doubt that, had he devoted his life to art, he would have attained a high position-but that would have been at the expense of his outstanding contributions to ophthalmology. It is difficult for one who is proud to claim the title of a friend to convey the charm of Spicer's personality. Of massive build and sedate demeanour, always unperturbed and somewhat slow of speech, he was full of kindliness and humour. It was a unique experience to travel abroad with him and witness his enjoyment of everything--including the 'good things' of life."

\section{NOTES}

The Vitello. THIs medal, of which we give an illustration, Medal has been presented to Mr. Leslie Paton by Professor Szymanowski of Warsaw. It has been struck to commemorate the 400th anniversary of the publication of Vitello's book in 1535 .

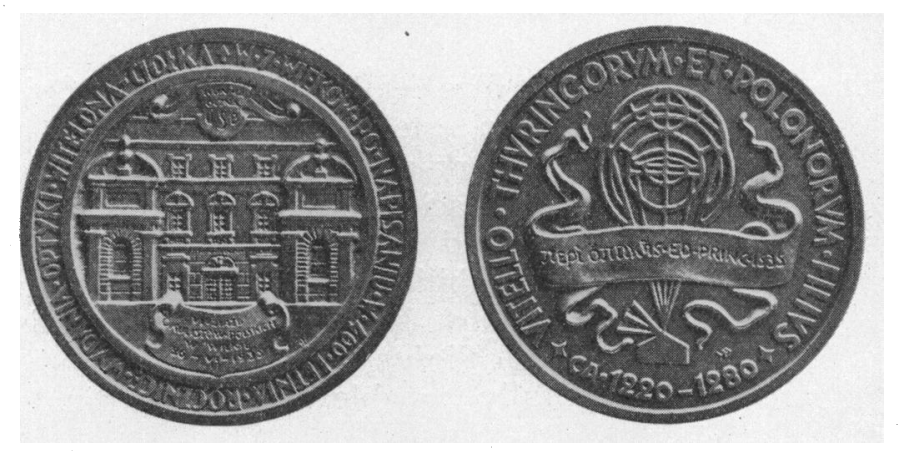

